\title{
Adoption of ICT in Supporting Ideation Skills in Conventional Classroom Settings
}

\author{
Gisli Thorsteinsson ${ }^{1}$, Tom Page ${ }^{2}$, Andrei Niculescu ${ }^{3}$ \\ ${ }^{1}$ University of Iceland, \\ v/Stakkahlid, 101, Reykjavik, Iceland \\ cdt@hi.is; \\ ${ }^{2}$ Loughborough University, \\ Loughborough, Leicestershire, LE11 3TU, UK \\ t.page@lboro.ac.uk; \\ ${ }^{3}$ Spiru Haret University, \\ 13 Ion Ghica Street, Bucharest 3, Romania \\ andreiniculescu@hotmail.com
}

\begin{abstract}
This article puts forward a case study of four related lessons, using a Virtual Reality Learning Environment (VRLE) to enhance students' ideation skills in Innovation Education (IE) in a conventional classroom. The following research questions are answered.

1. How could the VRLE be used with $I E$ material in a conventional classroom?

2. What pedagogical factors influence the innovation process and where the VRLE is used?

The lesson content is described and the overall aims, objectives and research questions stated. The specific data collection methods are explained. Subsequently, triangulated findings are reported as categories and results are discussed and analysed.
\end{abstract}

Keywords: Innovation Education, case study lessons, Virtual Reality Learning Environment, Pedagogy, Innovation process, Ideation.

\section{Introduction}

Innovation Education (IE) has become a specific subject area in the Icelandic national curriculum since 1999. The aim is to develop students' skills to identify needs and problems in their environment and to come up with new solutions. A specific Virtual Reality Learning Environment technology (VRLE) has been prepared to support students work. This VRLE supports online collaboration and helps students to develop drawings and descriptions of solutions (Thorsteinsson et al., 2004).

As the VRLE is relatively new it is important to assess its use and value in supporting students' ideation in a conventional context. The authors run several lessons to identify pedagogical issues of using the VRLE to support ideation within IE and to identify how it affects the already established pedagogy.

Many researchers consider that VRLE can support education. One of its main values is to favour constructivist-learning and computer cooperate supportive learning. It also has potential to support unlike types of learners (Page et al., 2008). Most research studies have observed whether a VRLE is a successful educational technology (Winn 1993). Other research works have been based on longitudinal case studies that developed virtual worlds for schools. Research studies on using VRLE's for school education are still few. So far, the authors have not found any regarding supporting ideation in the context of IE.

The article firstly describes the specific VRLE used for the enquiry. Secondly it reflects on the literature. Subsequently, overall aims, objectives and research questions are stated and the data collection methods explained. Finally, findings are discussed and the research questions answered.

\section{The Specific Software Used for the Enquiry}

The VRLE was established to be a tool to facilitate ideation and host online IE materials in order to facilitate the innovation process. Specific online workshops, based on an underlying database, were built to enable the formation of teacher's and students' online communities (see Figure 1). 


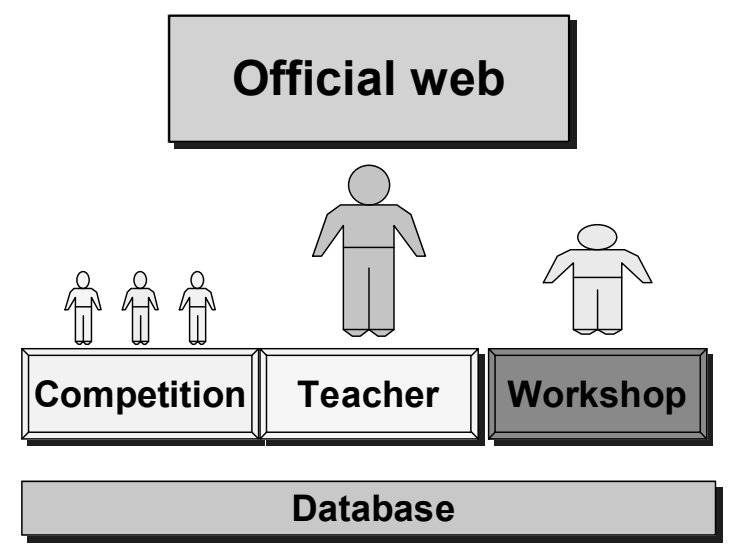

Figure 1. The basic structure of the VRLE.

The VRLE has management characteristics, in the form of online workshops both for students and teachers (Thorsteinssonet al., 2004). The teachers' workshops enable the teachers to support the students when working through the innovation process, keeping track of their work and evaluating their progress and achievements. The student's workshops are personal learning spaces inside the VRLE. The foundation of these workshops was based on the possibility to use computer technology to reinforce identification of needs, and development of solutions. The tools developed for this purpose have the names "My Needs" and "My Ideas" (see Figure 2).

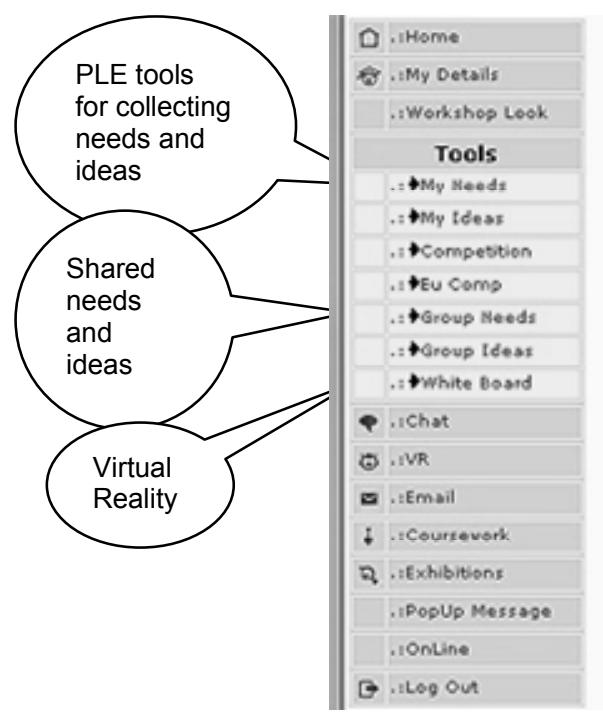

solutions they are working on and store them. From their workshops students can use many communication tools such as chat room, emails, set up "pop up" messages and enter the 3D virtual reality part of the VRLE (Thorsteinsson et al., 2006). The VRLE offers both asynchronous and synchronous communication and interactions, both between students and teachers and students themselves. The participants can communicate both within the VRLE and with the world outside the school. Figure 2 shows an example of the individual's personal learning space.

\section{The Pedagogy of Innovation Education}

IE is based on identifying needs and problems in students' environments and finding suitable solutions (Thorsteinsson and Denton, 2003). The foremost importance of the pedagogy of IE is to improve students' ideation through the innovation process (Gunnarsdottir, 2001). Subsequently students are meant to become better prepared to deal with their world and take part in society (Page, et al. 2008).

IE is intended to teach ideation skills in the context of innovation activity, and such skills

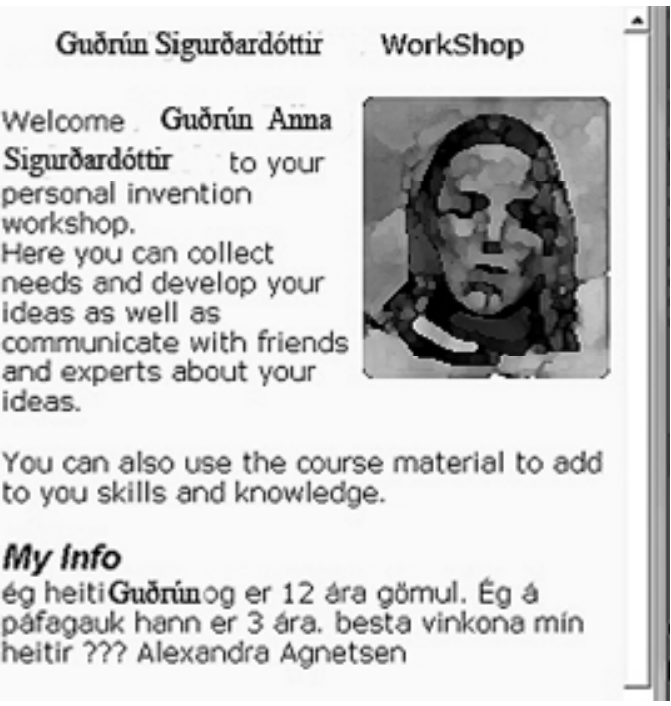

Figure 2. The students' workspace inside the VRLE

The students can edit needs and ideas/solutions with specific drawing tablets (CAD) and store them in their VRLE's personal database. With webcams they can also produce graphic representations of are integrated at all stages. The flowchart below shows the fundamental steps:

1. Identifying needs and problems;

2. Brainstorming;

3. Finding the primary solutions; 
4. Ideation drawings or modelling to develop the technical solution;

5. Making a description of the solution;

6. Presentation of the work. specific instruments used are listed against the research questions in Table 1.

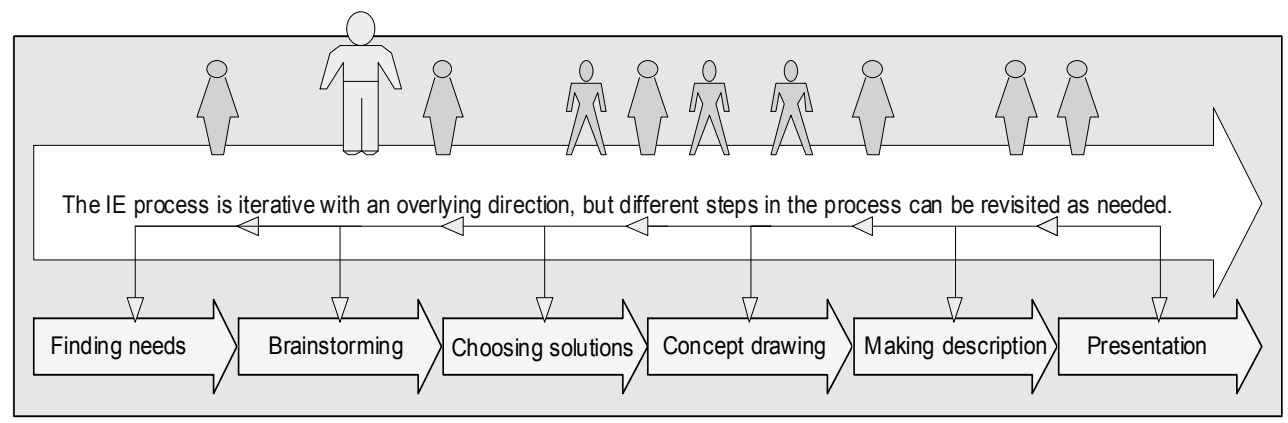

Figure 3. Students learn through the innovation process.

\section{Undertaking the Case Study Lessons}

The research study consisted of a series of four 90-minute related after-school, case study lessons, set up as an $I E$ course using the $V R L E$. The lesson sequence was:

1. Introduction and training in using the VRLE.

2. Individual students work out solutions using the VRLE.

3. The students test the VR element of the VRLE.

4. Individual students develop solutions for an exhibition in the VRLE.

The aim of the project was to recognise pedagogical issues when the VRLE was used to enable ideation in the conventional classroom.

The objective of the case study series was:

a) To develop an understanding of the pedagogy relating to the use of the $V R L E$ in supporting the development of ideation skills within $I E$.

The research questions for the case study series were:

1. How could the VRLE be used with IE material in a conventional classroom?

2. What pedagogical factors influence the innovation process and where the VRLE is used?

\section{Data Collection Instruments}

Varied data was needed to triangulate the research and strengthen reliability. The
Table 1. Data collection methods used in the enquiry.

\begin{tabular}{|c|l|l|l|}
\hline & Data Sources & Q1 answer & Q2 answer \\
\hline 1. & Screen captures in the VRLE & $\mathrm{X}$ & $\mathrm{X}$ \\
\hline 2. & Interviews with the teachers & $\mathrm{X}$ & $\mathrm{X}$ \\
\hline 3. & $\begin{array}{l}\text { Interviews with students } \\
\text { group about the course and } \\
\text { their work }\end{array}$ & $\mathrm{X}$ & $\mathrm{X}$ \\
\hline 4. & The researchers logbook & $\mathrm{X}$ & $\mathrm{X}$ \\
\hline 5. & $\begin{array}{l}\text { Drawings and descriptions } \\
\text { from students }\end{array}$ & $\mathrm{X}$ & $\mathrm{X}$ \\
\hline 6. & $\begin{array}{l}\text { Video recordings in the } \\
\text { classroom }\end{array}$ & $\mathrm{X}$ & $\mathrm{X}$ \\
\hline 7. & Data from the VRLE & $\mathrm{X}$ & $\mathrm{X}$ \\
\hline 8. & The Inventors Notebook & $\mathrm{X}$ & $\mathrm{X}$ \\
\hline
\end{tabular}

Open coding was used in the process of data analysis based on grounded theory principles. In open coding the researcher forms initial categories of information about the phenomena being studied (Creswell, 1998). He stays with an open mind to find as many ideas and issues as possible. Similarities in the outcome are classified into main categories and used for discussions, conclusions and feed forward (Emerson R.M., 1995). The data was used as follows:

The raw data was collected. Data from each source was then summarised; for example, there were two teacher interviews, which were summarised separately and then used to generate categories together. These categories were then discussed and conclusions drawn. The process was repeated for all the data sources listed above. Finally, the categories from all data sources were brought together under overall categories. These categories were then used to triangulate the findings and were analysed in relation to each other and the literature and conclusions were drawn. 


\section{Findings}

The main pedagogical categories established through the analysis of the data were:

a) Teacher's preparation;

b) Teacher's role and teaching handling;

c) Computer literacy;

d) Motivation;

e) Identifying needs and problems / homework;

f) Drawing;

g) Ideation;

h) Use of the VRLE;

i) Collaboration.

\section{Discussing Categories Emerging from the Data}

\subsection{Teacher's preparation}

The VRLE may be relatively user-friendly, as the teacher stated in one of the first interviews. However, he also reported his need for more time to prepare lessons; this is more an issue of teacher confidence. In order to establish the teacher's confidence, pre-training is vital both in managing the VRLE hardware and software within the school environment.

In the case study series, the teacher needed more time to prepare himself, the computer facilities and the VRLE software for the lesson; nevertheless, his own experience in running such lessons can also be informative in training. This includes learning the general operation of the computer system, such as setting up emails. However, this can easily cause a conflict of roles between tutor and administrator. The case study series was an after-school activity and thus it was difficult for the teacher to find time to fit it in his schedule. To run such lessons could also be tiring for a teacher in a full-time position and it may be better to run such classes within school time.

\subsection{Teacher's role}

The teacher's role is more complicated in the context of using the VRLE in the conventional classroom. In the interview, the teacher talked about role conflicts between being a computer administrator and a tutor. As the students were self-reliant and more capable than he expected, the teacher found he was not always active in lessons.
The teacher used multiple teaching methods; at the beginning of the lesson he used direct instruction, but also requested collaborative work from the students. He tried to make the students self-reliant by teaching fundamentals skills needed for working on the VRLE; this gave him time to administer the VRLE software and hardware. This was supported by the IE based VRLE, which provided a guiding structure for students. Also, the teacher was always nearby when the students needed help. From this experience, he realised that he could have demanded more from the students, had he known their computer ability.

\subsection{Computer literacy}

The students' computer literacy enabled the teacher to operate as a facilitator. It was unnecessary to spend time in teaching the use of the hardware and software. The teacher reported he needed more training in the using of the $V R L E$ and more preparation time; this was the case, even though this teacher was also the school ICT co-ordinator and, it may be assumed, of above-average computer literacy and with an adequate ability to manage the system and hardware. It may well be inferred that normal subject teachers would find the use of the VRLE more difficult and thus require more training and practice / preparation time.

\subsection{Motivation}

The students enjoyed the course and requested that $I E$ be made a compulsory subject. The students acknowledged that the course was new and different and found the process of $I E$ interesting. However, it is difficult to differentiate this interest from the motivation caused by experimental/novelty effects (Cohen, 2001). Nevertheless, motivation appeared to play a significant role in the students' demonstrated capability. The students also showed interest in having the IE-VRLE course as an open and distance course; working at home on their computer. This is an interesting point for the authors, as the VRLE has not been used as a tool for open and distance learning; however, it may offer new possibilities for other schools. 


\subsection{Identifying needs and problems/ homework}

The study showed that students' notebook is an important tool that supported communication and collaboration with parents and is also an important medium to transport identified needs and problems from home to school. It was also a great help in starting lessons. The students' notebook also increased the students' interest in identifying needs and ideas at home; they found it easy to use and practical.

The students used the VRLE at home; they recorded ideas and solutions and tried to enter the VRE. However, most of them did not possess the appropriate graphics card and thus were not able to use the VRE adequately.

\subsection{Drawing}

The students quickly learned to use the CAD program and the drawing tablets through experience, but their drawings were inaccurate; they showed sketches of initial solutions. However, further training might give a better outcome and increase the students' ability to develop the solutions. Graphics tablets were better than using a mouse, but there may be much better equipment available, closer to the traditional method of sketching with a pencil. The students experienced difficulties drawing inside of the VRE, because they were not used to using the CAD programme. Better computer-based drawing equipment that might actually bring students closer to the natural way of sketching may possibly exist.

\subsection{Ideation and Innovation Education}

The teacher was convinced that students' motivation for the course positively affected their ability to find new ideas. They had quickly understood the Innovation Process and were able to identify needs and problems in their own environment. Therefore, they found their ideas easily. The novelty of the students' ideas was doubted by the parents, and this implied that some of the parents might not have understood the educational value of the $I E$ course for the students. The identified needs and solutions at home were useful in starting the $I E$ lessons, as input for the brainstorming sessions. Short brainstorming sessions were also useful to refresh the students when they got tired. An interesting input from the teacher referred to the usefulness of ideation skills for subjects other than IE. In fact, IE is now part of the general chapter of the National Curriculum in Iceland and can be incorporated into all subjects.

\subsection{Use of the VRLE}

Good computer facilities enabled the students' work in the case study series. The students had no difficulty in using the Managed Learning part of the VRLE, once they got their email accounts open. The teacher gave them basic training, but their own experiences helped them in using the $V R L E$ and the drawing tablets. It was, however, more difficult for them to use the VRE part of the VRLE, when they were asked to design together; using an avatar inside the VRE is difficult at first. However, the students were happy, as it was fun for them. Being able to speak between computers via headsets helped the students to work inside of the VRLE, as it enabled their collaboration. However the teacher had to be aware of the possibility of outsiders manipulating the VRE's security.

\subsection{Collaboration}

The students were communicative and collaborated well together inside the MLE: the multimodal possibilities for communications may well have enhanced communications and collaboration. The group did have problems working as a group inside the VRE; the smaller the group, the better the students were able to work together.

The students used the possibilities for sharing needs and problems with each other inside the VRLE. They could also use brainstorming to communicate needs and ideas, both inside the classroom and inside of the VRLE as two parallel worlds.

When using innovative teaching methods, instructors need to be supported by their authorities and colleagues. The teacher in the case study series, whilst an experienced user of ICT, reported that he needed more time to practice and prepare (Bailey et al. 2004). The headmaster of this school supported the IE course and was interested in making IE a compulsory subject. 


\section{Answering the Research Questions}

Using various data collection methods provided evidence which enabled triangulation inside the established categories. In the following sections, the research questions for the case study series are answered:

The research questions for the case study series were:

1. How can the VRLE be used with IE material in a conventional classroom?

2. What pedagogical factors influence the innovation process when the VRLE is used?

\subsection{Question one}

The teacher's observations and the lesson plans, the interviews with the students, and the teacher, the logbooks and the students work in the $V R L E$ database all provided information about how the students used the VRLE for the IE work: the diagram below shows this process. The arrows show the path the students took; they incorporated methods from the traditional IE. As the diagram shows, there are many other possibilities for $I E$ work: one would be to use the VRLE tool for open and distance educational $I E$ courses.

This model connects the home environment and the school together; the students originated their ideas at home by identifying needs and problems and brought them to school. They recorded ideas in the IN and uploaded them to the VRLE database from home. This highlights the underlying $I E$ pedagogical background and the relation to the constructivist theories identified in the literature.

\subsection{Question two}

The main pedagogical factors that arose in the data were: computer literacy, managing the VRLE in the school context, and the role of the teacher.

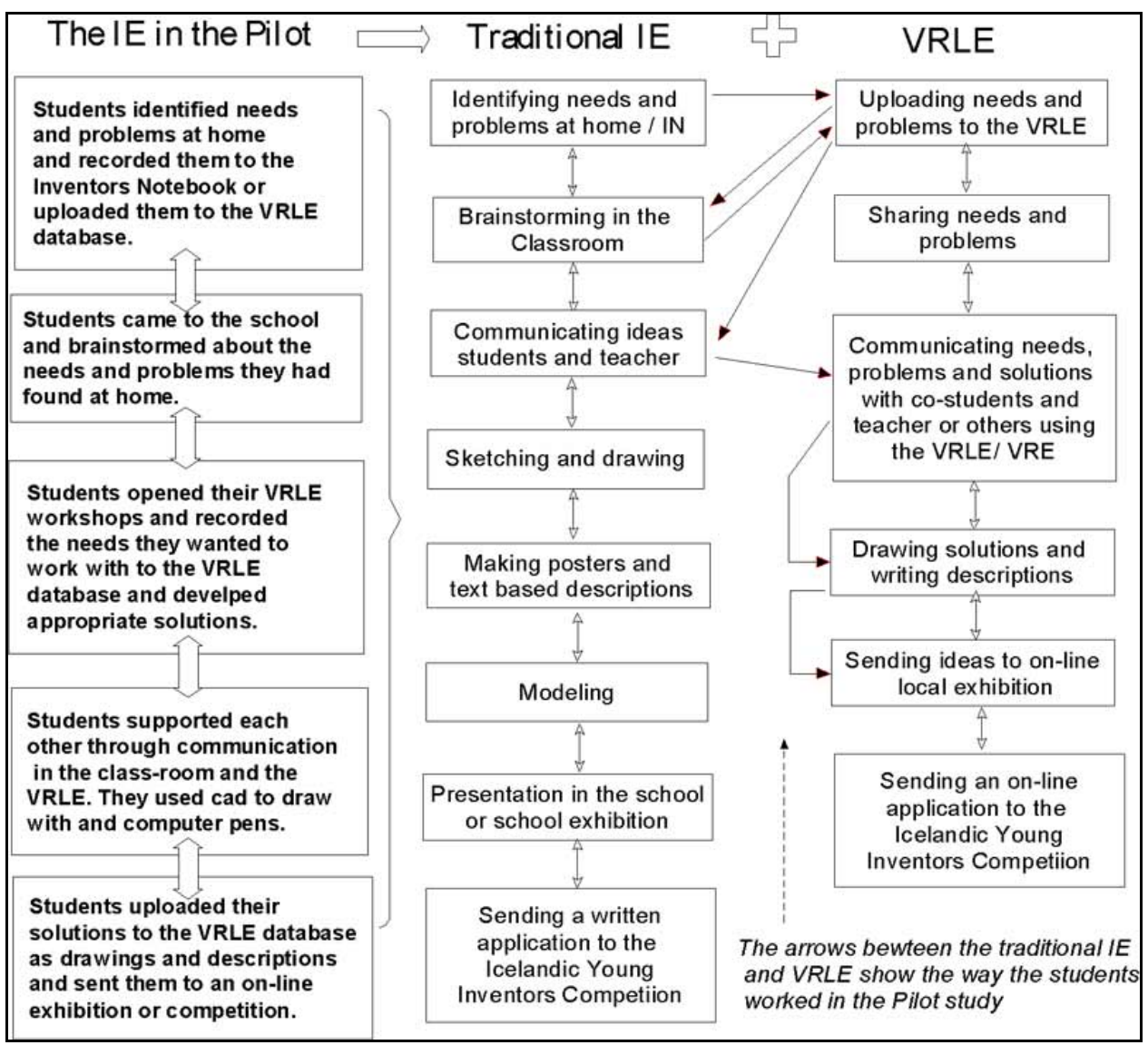

Figure 4. The way students used the VRLE to support their work inside of the innovation process (note the arrows between traditional IE and VRLE). 


\subsubsection{Computer literacy}

Interviews with students and teacher, in addition to observations, indicated that the students easily learned to use the VRLE and the CAD software: little teacher assistance was needed. However, the students did experience difficulties in using their computer mouse to draw, and the CAD they used was too basic. At the beginning of the course they used a mouse, and later on a pen that connected to the computer. With this, the students had to look at the screen as they were drawing: this shows how the new VRLE technology can be used in schools for pupils from class seven upwards.

\subsubsection{The teacher has to be able to manage the VRLE within school}

The interviews with the teacher, his logbook, and classroom observations showed the importance of the teacher managing the VRLE hardware and software in the school. Appropriate facilities are needed to run the system, such as graphic cards, headsets, and digital pens; however, this represents extra cost for the school. Introducing such new approaches and technology does require a great deal of effort on the teacher's behalf. Training would be necessary, in order to enable teachers to manage the hardware and the software.

\subsubsection{The teacher is the key to successful IE lessons}

In the interviews with the teacher, and in his logbook, he mentioned the importance of being trained to use the VRLE. Also, it is necessary for him to understand the innovation process, to be able to guide the students. In his observations, the author could see a lack of teacher understanding of the innovation process. However, he was usually in the role of facilitator rather than instructor. The teachers' self-confidence was identified as important. This teacher had experience as an ICT teacher and was the schools administrator, but it was noted that he often lacked confidence in running the IE course and when dealing with the software and hardware.

The VRLE was found to be user friendly and enabled the students to be self-reliant. Nevertheless, the teacher still had to use familiar pedagogical principles, such as giving clear instructions. It was important to link the students' homework with their activities inside the VRLE through brainstorming sessions in the classroom. After this, the students could work independently. When they had to undertake their work in the VRLE, they sometimes got tired after 20-30 minutes, but, by using short brainstorming sessions, the teacher found it was possible to refresh them.

\section{Conclusion}

The teacher's role was identified as a fundamental category. This refers to the teacher's responsibilities to manage and enable the context of teaching and learning. It is often described in relation to certain pedagogical theories. The Oxford Dictionary (2008) defines 'teacher' as: "One who or that which teaches or instructs; an instructor; one whose function is to give instruction". This definition is instructionally orientated, rather than related to pedagogical theory, or classroom activity. The research showed the teacher's role in the VRLE context had different dimensions including technician, planner of instructional contexts, giver of information and facilitator. It echoes Jonsdottir (2005) who showed the teacher's role in $I E$ as significant in creating circumstances to support students' progress.

Gunnarsdottir's work (2001), furthermore, underlined scaffolding students' learning and their relationship with the teacher as important. She saw this in relation to Vygotsky's social constructivist theories, as the teacher was able to support the students in their 'zones of proximal development' (Vygosky,1978) and consequently facilitate their ideation. The teacher may take on, simultaneously and sequentially, several roles that are often interconnected and closely related one to another.

Part of the research was to examine and discover the new roles of the $I E$ teacher in a ICT learning context. Therefore this had not been defined before the course started. This may have caused pedagogical and technological difficulties for the teacher and made him insecure in his work. The Kiryat Malachi study (Glick, 2008) indicated that teachers should go through training and become fully familiar with the computer 
program. Their roles in the course should also be clearly defined.

It was identified that using the VRLE depends largely on the teacher's ability to manage it. Other research similarly indicates that teachers have many roles and responsibilities in the context of blended learning to coordinate in order to achieve e-learning success. A delicate and informed balance between these roles is vital to the success of e-learning (Bonk et al., 2002). Johannsdottir (2008) pointed out that teachers need ongoing education, especially with regards to the new technologies in schools. The teacher has to switch between being a tutor and a facilitator or supervisor with general knowledge in ICT, able to support the students in their studies. Teachers also have to be able to constantly adapt to new circumstances and learn to develop the curriculum accordingly. The focus moves from instructional teaching methods to supporting students' independent studies (Matthiasdottir, 2001b).

The ideation process provided the framework for using the VRLE for IE. In managing this the teacher had to develop his roles. Some, related to using the VRLE, were more demanding compared to his conventional teaching. The teacher had to:

- organise the courses;

- prepare for the lessons;

- find the appropriate teaching methods and use them differently;

- solve technical problems, both in hardware and software;

- teach fundamental skills and train students in IE and using the VRLE;

- teach the IE process inside the VRLE;

- find appropriate teaching methods during lessons:

- be both an instructor and facilitator;

- engage parents in homework;

- conduct brainstorming and refocusing students (partly in the VRLE);

- support the ideation process by discussing problems, needs and solutions.

The novelty and complications of the teacher running lessons within a framework of blended IE learning appeared to cause role conflicts in him. There was evidence for increased insecurity and he became more self-critical. $\mathrm{He}$ was in a process of finding and developing his teaching methods and had to face many problems, mostly caused by the novelty of the new technology. He both had to assist students inside the classroom and the VRLE and support their self-reliance. Nevertheless, he had experiences as an ICT teacher and probably more capable than was a normal classroom teacher. In addition, he was the schools computer administrator. In relation to curriculum development we need to be aware of these stresses as some teachers may have been unable or unwilling to manage them (Page et al. 2008). Kennedy (1996, p87) recognized this in his study on curriculum changes: "Teachers then can be powerful positive forces for change but only if they are given the resources and support which will enable them to carry out otherwise the change is more likely to cause stress and disaffection...".

Our pedagogical knowledge and understanding of using VRLE in the context of IE has to be developed further. Many opportunities lie in the use of the software. The technology is already part of young people lives, but less used in general education (Thorsteinsson et al. 2007). Using the VRLE depends on the teacher's capability to use it. Therefore course material has to be developed for training teachers so they can use it and fully implement it in schools. It is also essential to discover the possibilities that lie in the helpfulness of such technology for open and distance education. This project has identified the VRLE as useful to support the process of ideation. However, the indications from the research are that we need to explore and understand the application of the VRLE further.

\section{REFERENCES}

1. BAILEY, L., C. DAY, T. DAY, A. GRIFFIN, P. HOWLETT, M. KANE, C. KIRK, N. MCCULLOUGH, B. MCKIERNAN, T. MCMULLEN, $\mathrm{K}$. PERFECT, E. RAMSEY, R. WOOD, Research Report RR595, Using ICT in Schools: Addressing Teacher Workload Issues, Pricewaterhouse Coopers, DfES Publications, Nottingham 2004.
2. BALOG, A., C. PRIBEANU, Developing a Measurement Scale for 
the Evaluation of AR-based Educational Systems. Studies in Informatics and Control, Vol. 18 (2), June 2009, ISSN 1220-1766, pp. 137-148.

3. BONK, C. J., T. M. OLSON, R. A. WISHER, K. L. ORVIS, Learning from Focus Groups: An Examination of Blended Learning. Journal of Distance Education, Vol. 17 (3), 2002, pp. 97-118.

4. COHEN, L., L. MANION, L. MORRISON, Research Methods in Education (fifth edition), Routledge, London, 2001.

5. CRESWELL, J. W., Qualitative Inquiry and Research Design: Choosing among Five Traditions. Thousand Oaks, CA, Sage, 1998.

6. EMERSON, R. M., R. I. FRETZ, L. L. SHAW, Writing Ethnographic Fieldnotes. University of Chicago Press, Chicago, 1995.

7. GLICK, D., An Effective Blended Learning Solution Overcoming Pedagogical and Technological Challenges in a Remote Area - A Case Study. Proceedings of the Chais conference on instructional technologies research 2008: Learning in the technological area. Eshet, Y.A., Caspi, A., Geri, N. (Eds), The Open University of Israel, Raanana, 2008.

8. GUNNARSDOTTIR, R., Defining the Phenomenon. Unpublished theses, Leeds University, 2001.

9. JOHANNSDOTTIR, TH. J., ÁhrifNetsins á menntakerfið, 2008, Retrieved (5 April 2009) from http://ust.khi.is/tjona/ahrifnet.htm.

10. JONSDOTTIR, S. R., Nynamsgreinverourtil. Nyskopunarmenntígrunnskola. Unpublished M.A., University of Iceland, 2005.

11. KENNEDY, C., Teacher Roles in Curriculum Reform. English Language Teacher Education and Development, Vol. 2 (1), 1996.

12. MATTHIASDOTTIR, A. Kennslurými. UT fyrirframhaldsskóla, 2001b, Retrieved (5. April 2009) from http://www.lara.is/utn/tenglar/LTilKennara.htm.
13. PAGE, T., G. THORSTEINSSON, A. NICULESCU, Management of Knowledge in a Problem Based Learning Environment, Studies in Informatics and Control, Vol. 18 (3), Sept. 2009, ISSN 1220-1766, pp 255-262.

14. PAGE, T., G. THORSTEINSSON, A. NICULESCU, A Pedagogical Consideration of Technology Enhanced Laboratory Work in Technology Education, Studies in Informatics and Control, Vol. 17 (1), March 2008, ISSN 1220-1766, pp 85-94.

15. The Icelandic National Curriculum. Innovation and Practical use of Knowledge, Menntamálaráðuneytið. Reykjavik, 1999.

16. The Oxford English Dictionary, 2008, Retrieved (5 April 2009) from http://www.oed.com/

17. The Webster Dictionary, 2005, Retrieved (5 April 2005) from http://www.m-w.com/

18. THORSTEINSSON, G., H. DENTON, The Development of Innovation Education in Iceland: a Pathway to Modern Pedagogy and Potential Value in the UK. The Journal of Design and Technology Education, Vol. 8 (3), 2003, pp 172-179.

19. THORSTEINSSON, G., T. PAGE, Use of On Line Facilities in InnoEd. First International InnoEd Conference: Dimensions of Flexibility and Creativity for Preferable Futures, University of Leeds, 2004, pp 301-309.

20. Thorsteinsson, G., T. Page, A. Niculescu, Using Virtual Reality for Developing Design Communication, Studies in Informatics and Control, Vol. 19 (1), March 2010, ISBN 1220-1766. pp 93-106.

21. THORSTEINSSON, G., T. PAGE, M. LEHTONEN, A. NICULESCU, Innovative Technology Education in a Virtual Reality Learning Environment, Studies in Informatics and Control, Vol. 16 (3), Sept. 2007, ISBN 1220-1766, pp 297-306.

22. VYGOTSKy, L. S., Mind in Society: The Development of Higher 
Psychological Processes, Harvard University Press, Cambridge, MA, 1978.

23. WILLIS, J., A Framework for TaskBased Learning, Longman, London, 1996.

24. WINN, W., A Conceptual Basis for Educational Applications of Virtual Reality. Human Interface Technology Laboratory, Washington Technology Centre, University of Washington, 1993.
25. YI, M. Y., Y. HWANG, Predicting the Use of Web-based Information Systems: Self-efficacy, Enjoyment, Learning Goal Orientation, and the Technology Acceptance Model. Intl. Journal of Human-Computer Studies, Vol. 59 (4), 2003, pp 431-449. 